\title{
EVIDENTIALITY AND FLEXIBILITY OF SOURCE REPORTING
}

Evidentiality and flexibility of source reporting

\author{
Castelain, Thomas \\ Instituto de Investigaciones Psicológicas, Instituto de Investigaciones Lingüísticas, \\ Universidad de Costa Rica, San José Costa Rica \\ thomas.castelain@ucr.ac.cr \\ https://orcid.org/0000-0001-9415-1771
}

Floyd, Simeon

Universidad San Francisco de Quito, Quito Ecuador

sfloyd1@usfq.edu.ec

https://orcid.org/0000-0002-9739-2914

Mercier, Hugo*

Institut Jean Nicod, Département d'études cognitives, ENS, EHESS, PSL University, CNRS, Paris France

hugo.mercier@gmail.com

https://orcid.org/0000-0002-0575-7913

*Corresponding author: Hugo Mercier, hugo.mercier@gmail.com 


\title{
EVIDENTIALITY AND FLEXIBILITY OF SOURCE REPORTING
}

\begin{abstract}
The reporting of the sources of our statements - whether we have, e.g., seen something or been told something - plays an important role in communication. The inaccurate reporting of sources is often associated with the spread of inaccurate beliefs, as when rumors are attributed to a non-existent credible source. Experiments have revealed that participants display a substantial amount of flexibility in the reporting of sources, in particular by attributing to themselves ideas they have acquired from others. However, these participants belonged to large-scale societies, and they spoke languages without grammatical evidential marking. Both factors might increase flexibility in source reporting. To test whether members of small-scale societies speaking languages with evidential marking also display flexibility in source reporting, we conducted two experiments with Quichua and Cha'palaa speakers in Ecuador. In both experiments, some participants acquired a belief through social transmission, and then had to communicate this belief to another participant. In doing so, very few participants mentioned the social source of their belief, whether explicitly, or by using the relevant evidential markers. These results show that flexibility in source reporting is a cross-culturally robust phenomenon, and that grammatical evidential marking does not appear to strongly affect this flexibility.
\end{abstract}

Keywords: Source monitoring, source reporting, evidentiality, cultural transmission.

Word count: 9751 


\section{EVIDENTIALITY AND FLEXIBILITY OF SOURCE REPORTING}

Evidentiality and flexibility of source reporting

People in societies around the world rely on a huge amount of socially transmitted information. The reporting of the sources by which people acquire information plays an important role in deciding how much weight to put on that information. For instance, we may be more inclined to take seriously a first-hand report of "I saw Sisa, she's back home" rather than a second-hand report, "Someone told me Sisa is back home." If accurate source reporting is obviously crucial in academia or journalism, source attribution also plays a major role in informal communication, for example the transmission of accurate rumors (e.g. Caplow, 1947; DiFonzo \& Bordia, 2002).

One of the forces that keeps source reporting accurate is epistemic vigilance, the suite of cognitive mechanisms with which people evaluate communicated information (Mercier, 2020; Sperber et al., 2010). First, if a piece of information turns out to be inaccurate, we may hold the speaker more accountable if she reported on it first-hand (Altay \& Mercier, in press). Second, in some circumstances at least, we blame speakers who do not report sources accurately (Altay \& Mercier, in press; Shaw \& Olson, 2015; Silver \& Shaw, 2018). Under pressure to maintain a reputation of trustworthiness, speakers may endeavor to specify whether they personally observed the evidence for communicated information, someone else told them, they inferred it, assumed it, are only speculating about it, read about it, dreamed about it, and so on (on the non-grammatical evidential strategies of English, see Chafe \& Nichols, 1986).

In spite of this, source reporting can also be flexible, as people portray information from different perspectives and may emphasize one source or omit or modify another based on different social contingencies. For example, one study found that pro-vaccine supporters, having different options, often defend their stance by citing personal information, even though 


\section{EVIDENTIALITY AND FLEXIBILITY OF SOURCE REPORTING}

they are actually drawing on information acquired second hand from medical professionals (Fadda et al., 2015). The potential for source flexibility-i.e. when people present statements as having different sources from their initial or primary sources - may open the door to the spread of inaccurate information. For example, misleading rumors are often introduced by a false attribution to a credible source (e.g. Morin, 1969; see also Altay et al., submitted).

Flexibility in source reporting may arise for a variety of reasons. So far, the most commonly studied reasons have been cognitive constraints on memory, in particular in young children (e.g. Robinson \& Whitcombe, 2003; Whitcombe \& Robinson, 2000), or when the source information is subtly manipulated (e.g. Loftus, 2005). Flexibility in source reporting can also arise because of other types of cognitive constraints. Some of our beliefs stem from a combination of sources of information, some direct (perception), others indirect (inference, hearsay). In such cases, it would be both cognitively and communicatively overly complex to attempt to accurately present the sources of one's belief. To cope with this complexity, people might use shortcuts, such as describing any belief that has both direct and indirect sources as only having direct sources (de Haan, 1998; Faller, 2002).

People can also present sources flexibly even when no memory or cognitive constraint would preclude them from accurately reporting sources - for example, when they have clearly and very recently acquired a belief socially. In such cases, source flexibility might be motivated, in that people might be attempting to achieve desirable outcomes by flexibly reporting sources. For example, a speaker might attempt to convince the audience by ascribing their ideas to an authoritative source, or, on the contrary, attempt to pass as more competent than they are by attributing to themselves someone else's idea (Altay \& Mercier, in press). In such cases, audiences believe that source transmission can, and ought to be, accurate, and they evaluate negatively people who portray an idea they have acquired through testimony as being their own (Altay \& Mercier, in press; Shaw \& Olson, 2015; Silver \& 


\section{EVIDENTIALITY AND FLEXIBILITY OF SOURCE REPORTING}

Shaw, 2018). Note that, as is true of motivated reasoning (Kunda, 1990; Mercier \& Sperber, 2011; see also Mahr \& Csibra, 2017), motivated flexibility in source reporting does not necessarily imply conscious strategizing.

Source flexibility—in particular motivated source flexibility—can also be dampened by several factors. If a speaker expects that the audience knows the actual source of their beliefs, they are less likely to be flexible, accurately reporting the source of their belief instead (Altay \& Mercier, in press). Linguistic factors may also play into how flexible source reporting can be. While it is possible to cite a source in all languages, not all of them have grammatical evidential marking, or evidentiality: the grammatical marking of information sources (57\% of the World Atlas of Language Structures sample, see de Haan, 2013). One way that evidentiality has been understood is that speakers of languages with grammatical evidentials must, in theory, always use grammatical markers to indicate their sources of information (e.g. whether they have seen something, inferred it, or been told about it) (see, e.g. Aikhenvald, 2004; Chafe \& Nichols, 1986; San Roque, 2019). However, a review of the literature on evidentiality reveals extreme diversity in the types and complexities of evidential systems (see, e.g. Wierzbicka, 1994), and some of the most current research suggests that knowledge-based grammatical marking is more sensitive to interactional issues than to information source alone. Some current research is attempting to re-conceptualize the category more broadly (e.g. Tournadre \& LaPolla, 2014), and some work now avoids the term "evidential" (e.g. Grzech, 2016). While we would maintain that at least one of the meanings associated with the markers called "evidentials" in the descriptive linguistic tradition has to do with information source, the results of controlled studies like the ones presented below can help us to further refine our understanding of evidentiality and inform descriptive research.

The very little research in controlled experimental settings that has been done on source flexibility has almost exclusively been conducted with standard psychology 


\section{EVIDENTIALITY AND FLEXIBILITY OF SOURCE REPORTING}

participants, usually speaking European languages that do not tend to have much if any evidential marking. This article tests source flexibility in communities speaking languages with evidential marking, seeking to answer the following question: Does having a language that forces its speakers to indicate the source of their statements make the speakers more likely to report accurate sources? In other words, does evidentiality dampen source flexibility by grammatically requiring that information source be specified?

After a short introduction to evidentiality, and a review of work on evidentiality and source flexibility, we review in more details the studies on flexibility in source reporting that have inspired the current experiments.

\section{Evidentiality and flexibility in source reporting}

Grammatical evidential marking has been referred to as "the linguistic encoding of epistemology" (Chafe \& Nichols, 1986), and ever since this category was first investigated researchers have asked questions about the broader social and cognitive implications of linguistic systems that require their users to mark aspects of knowledge and information. It is sometimes remarked, although usually not seriously, that speakers of languages with grammatical evidential categories are as a result "more truthful." Dixon, a linguist who has

described a number of languages with evidential systems, joked that if English had evidential marking it might make policework easier or politicians more honest (Dixon, 1997, p. 120). Many researchers have suggested that the features of one's language can profoundly affect cognition (e.g. Boroditsky, 2003; Imai \& Gentner, 1997; Lucy, 1992), although the presence of evidentials specifically has not been the main focus of such work. However, as Aikhenvald (2014) points out, evidentiality is a grammatical category and does not necessarily have a direct relationship to behavior (see also Aikhenvald, 2016, p. 323). Still, evidential usage, if it 


\section{EVIDENTIALITY AND FLEXIBILITY OF SOURCE REPORTING}

is detected as inaccurate, is sometimes subject to social rather than grammatical correction (Aikhenvald, 2012, pp. 271-272). This suggests that grammatical evidentiality might influence the flexibility of source reporting.

The few existing studies comparing source reporting in languages like English, without grammatical evidential marking, and languages like Turkish, with a grammatical direct (e.g. perception) / indirect (e.g. hearsay) evidentiality distinction, have not yet identified cross-linguistic differences in source flexibility (for a recent review, see Ünal \& Papafragou, 2018). In particular, in both types of language people tended to present indirectly acquired information as directly acquired information. However, the work conducted so far has focused either on young children (preschoolers: Aydin \& Ceci, 2013; Papafragou et al., 2007), or on tasks putting significant strain on memory (such as remembering dozens of new pictures: Ünal et al., 2016). As a result, the source flexibility exhibited in these studies might have been the result of cognitive constraints, rather than of social motivation.

\section{Motivated source flexibility}

If the majority of the experiments on source flexibility have focused on cognitive constraints, a few have looked at how people might flexibly report information sources in a more motivated manner. A series of studies, using a variety of materials — from general knowledge questions to perceptual tasks - has found that many participants present socially acquired information as if it had been personally acquired, or engage in other forms of source flexibility (Altay et al., submitted; Altay \& Mercier, in press; Claidière et al., 2017;

Dockendorff \& Mercier, in prep; Mercier et al., 2019). In all of these experiments, there were few memory constraints — remembering a simple piece of information for a few minutes—or 


\section{EVIDENTIALITY AND FLEXIBILITY OF SOURCE REPORTING}

no constraints at all - the source of information was still present when participants had to make their own statements.

An account in terms of motivated source flexibility is supported by the observation that participants were more likely to present a piece of information as being their own idea when motivated to appear competent (Altay \& Mercier, in press), and that these participants were then perceived as being more competent (Altay \& Mercier, in press). In other experiments, participants used flexibility in source reporting to make a piece of information more credible while controlling the reputational fallout if their interlocutor finds the information to be mistaken (Altay et al., submitted).

Crucially, all of these experiments have been conducted in languages with no grammatical evidential marking, in which presumably information source reporting is optional and periphrastically encoded (French and English in the studies cited above; although one study was conducted in Japanese, which can be considered to have some degree of evidentiality; see, e.g. Matsui \& Yamamoto, 2013). To investigate whether flexibility in source reporting is decreased by evidentiality, we conducted a series of experimentsinspired by some of the experiments mentioned above-with two populations whose languages have grammatical evidential marking. Moreover, our participants came from smallscale populations, another factor that might plausibly reduce flexibility in source reporting.

\section{Evidentials and source flexibility in small-scale societies}

There are at least two reasons why speaking a language with evidentials might limit flexibility in how we present sources. First, at the moment a statement is produced, being required to specify the source through evidential marking should leave less room for ambiguity, which in turn might prompt people to accurately report sources instead of 


\section{EVIDENTIALITY AND FLEXIBILITY OF SOURCE REPORTING}

choosing to explicitly report inaccurate sources. Second, such an effect, repeated over time by the constant use of evidentials, might make people accustomed to a higher level of accuracy in source reporting, as well as more attentive to information reporting practices.

Moreover, evidential use might play a particularly important role in small-scale societies like those considered here, where everyone knows one another. Compared to such societies, information in large-scale societies often circulates through many more, less easily identifiable intermediaries — as when a scientific finding goes from the members of a laboratory, to a scientific article, to a university's public relation office, to a scientific newspaper, to a tabloid. Schieffelin (1995) discusses how members of small-scale Kaluli society in Papua New Guinea initially found it difficult to talk about this type of anonymous transmission of information common in Western societies with their language's evidential system. Since the task is comparatively simpler when sources are fewer and more immediate, members of small-scale societies might be more likely to develop a habit of accurate source reporting.

Members of small-scale societies could also be generally more epistemically cautious when sharing opinions because the consequences of sharing mistaken opinions may be greater, and members of such societies have sometimes been noted to be reluctant to engage in unfounded speculations that they could be held accountable for (M. Cole et al., 1971; Luria, 1976; on avoidance of hypotheticals in Amazonian Kichwa, see, Nuckolls \& Swanson, 2014). These concerns for their epistemic reputation might be assumed to make members of smallscale societies more likely to accurately describe the sources of their assertions. Note that this is true whether or not they have evidentials, and opposes these societies to large-scale urban societies, even when evidentiality is present (e.g., Turkish, see Ünal \& Papafragou, 2018).

However, if evidential marking is usually described is as an "obligatory" coding of information source (e.g. Aikhenvald, 2004), it is only obligatory in that some languages 


\section{EVIDENTIALITY AND FLEXIBILITY OF SOURCE REPORTING}

require speakers to choose an evidential value. It has not been claimed that the accurate reporting of sources would be obligatory in such languages. Indeed, anthropological work in populations speaking languages with evidentials shows that at least some source reporting is not straightforward or strictly accurate, as when some Duna speakers in Papua New Guinea describe the fantastic origin stories of their tribes using marking for direct perception or egophoricity (San Roque, pers. comm., see also San Roque \& Loughnane, 2012; Gipper, 2014; Nuckolls \& Michael, 2012).

\section{The present studies}

We conducted two experiments in order to test whether members of a small-scale population speaking a language with evidential marking report sources flexibly, even in the absence of memory constraints, so that any flexibility observed would likely be motivated flexibility.

The first experiment is one in which source reporting is flexible among typical Western participants. Participants are asked to solve a logical task with an intuitive but incorrect answer. Participants are then provided with a good argument supporting the correct answer, which most accept. The participants are asked to produce a reason to support their final answer. Among the participants who have acquired this final answer socially, none mention the social source of their answer, recreating instead the argument provided as if they had discovered it on their own (Claidière et al., 2017). Here we use in lieu of logical task a conservation task previously used with similar small-scale populations (Castelain et al., 2016).

The second experiment is structurally similar: participants face a task in which most provide the wrong answer, accept the correct answer socially, and are then asked to provide a 


\section{EVIDENTIALITY AND FLEXIBILITY OF SOURCE REPORTING}

reason for this correct answer. However, the task used in this experiment should make it more difficult for participants to be flexible in presenting the source of their final answer. The task is perceptual instead of conceptual, and the correct answer is acquired not through argumentation, but through deference to a more competent individual. Yet most participants (in the U.S. and Japan), when asked to produce a reason to defend their final answer, fail to mention the social source of their beliefs, some using instead perceptual arguments (even though these arguments go against their initial answer) (Mercier et al., 2019). One of the conditions of this experiment was slightly adapted and used here.

\section{Populations studied}

All the participants involved in this study were members of indigenous communities living in the northwestern part of Ecuador. Some of the participants were speakers of Ecuadorian Highland Quichua (Quechuan family, referred to here as Quichua) while others were speakers of Cha'palaa (Barbacoan family). Speakers of Quechuan languages tend to live in settlements, villages and towns with well-defined elements of local indigenous culture, but also with long historical links to Spanish-speaking society. There are many diverse dialects of Quichua; our participants spoke Imbabura Quichua (see P. Cole, 1984), spoken in the northern province of Imbabura in communities traditionally dedicated to weaving, handcrafts, and agriculture and now to tourism and global crafts and textile sales (for background, see Colloredo-Mansfeld, 1999; Meisch, 2002; Parsons, 1945).

Cha'palaa is a member of a smaller language family, the Barbacoan languages of northern Ecuador and southern Colombia, whose speakers have historically been more isolated from Spanish-speaking societies in the Andean valleys due to their locations on the forested coastal slopes. The Chachi people, speakers of Cha'palaa, have migrated out of the 


\section{EVIDENTIALITY AND FLEXIBILITY OF SOURCE REPORTING}

Andes towards the coast, where they live in small settlements along the rivers of Esmeraldas province, dedicated to tropical agriculture such as plantains as well as hunting, fishing, and, in recent decades, logging (for background, see DeBoer \& Blitz, 1991; Floyd, 2010, 2014; Jijón y Caamaño, 1914).

While historically connected, Quichua-speaking and Cha'palaa-speaking societies are today quite distinct and not in close contact, offering two different settings in which to look at social information management. While both can be considered small-scale traditional societies, the Chachi society is much more isolated from national and international influence, while the Imbabura Quichua people are fairly intensely connected. The two languages also sometimes contrast sharply with each other, particularly in how they handle issues like person marking and argument structure (see Floyd, 2018), but they resemble each other in that both feature multiple options for grammatically marking knowledge-based distinctions that fall under the umbrella of evidentiality (P. Cole, 1984; Floyd, 2005, 2018).

\section{General Procedure}

Two native female experimenters (one in each community) were trained by two of the authors, and they conducted all the experiments. The experimenters interacted with the participants in their native language. The translation of the material from Spanish to Quichua or Cha'palaa was done by a native speaker, the back-translation by one of the authors with discrepancies resolved through discussion between two of the authors and a native speaker. The experiments took place in the village of each community in a room used for the purpose of the investigation. All the experiments were video-recorded. All the responses were recorded, transcribed and translated from Quichua or Cha'palaa to Spanish. Verbal informed 


\section{EVIDENTIALITY AND FLEXIBILITY OF SOURCE REPORTING}

consents were obtained from the participants and were video-recorded. Each participant received a locally appropriate payment for his or her participation.

\section{Experiment 1}

Experiment 1 confronts participants to a logical task which we expect most of them to fail to answer, based on previous results in analogous populations. Those participants will be referred as Generation 1. Those who fail are provided by the experimenter with the correct answer, either accompanied by an empirical argument—in the Argument Condition—or not— in the Authority Condition. We then observe how these participants from Generation 1, who have been provided with the correct answer by the experimenter, attempt to communicate the correct answer to another participant, belonging to Generation 2. In particular, we were interested in determining (i) whether Generation 1 participants would mention that they owed their belief to the experimenter, in particular (but not only) by using evidentials and, (ii) whether they would be more likely to do so in the Authority condition (in which the authority of the experimenter is the sole reason they accepted the belief) than in the Argument condition (in which they likely accepted the belief at least in part on the basis of the argument provided).

In a similar situation (albeit online, rather than in person), U.S. participants never mentioned the social source of their answer, whether in the equivalent of the Argument or of the Authority Condition implying instead the source to be a more direct, personal experience (Claidière et al., 2017). This experiment thus tests whether similar results will be obtained in a very different population: members of small-scale societies speaking languages with evidential marking. These cultural and linguistic differences might drive the present populations to mention the source, in particular in the Authority Condition, in which they do not have immediate access to a correct argument to explain the correct answer. 


\section{Method}

\section{Participants}

Ninety-six Quichua speakers participated in the experiment (73 females, Mage $=41.95$ years, $S D=14.24$, range $18-73$ years). All the participants originated from rural villages close to the city of Otavalo in the Province of Imbabura. All of them spoke some Spanish but their mother tongue was Quichua.

Ninety-six Cha'palaa speakers also participated to the experiment (47 females, Mage $=$ 37 years, $S D=14.70$, range $18-78$ years). All the participants lived in a village in the Cayapas River region of the province of Esmeraldas. All of them spoke some Spanish but the women and elder participants were mostly monolingual.

\section{Materials}

The conservation tasks used in this experiment are designed to assess the understanding of the invariance of physical quantities across physical transformations (Dasen, 1972; Piaget \& Inhelder, 1974). We used a weight/volume conservation task, in which participants must indicate how the water level in two glasses changes when one object is introduced in each glass. The objects differ in an irrelevant dimension, their weight, but not in volume; hence the correct answer is that the water rises as much in the two glasses (see Figure 1). The task used in this study was chosen based on results obtained by Castelain et al. (2016) with another traditional population (indigenous Maya), where it elicited a relatively low performance (around 30\% of correct answers). 


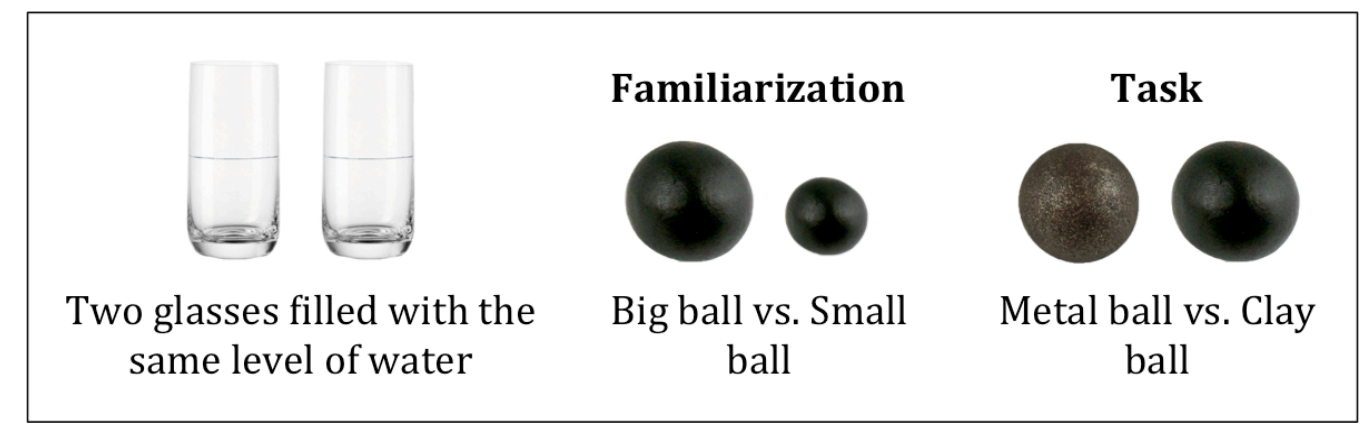

Figure 1. Materials used in experiment 1. Figure adapted from Castelain et al. (2016).

\section{Procedure}

Participants were put in pairs and randomly assigned to one of the two different groups called Generation 1 and Generation 2.

Phase 1. Each phase started with a familiarization phase. The first participant, belonging to Generation 1, was presented with the material, two glasses and two balls of clay (Play-Doh). The experimenter poured water in the glasses and said to the participant: "Here we have two identical glasses in which I will pour water. As you can see, the level of water is the same in both glasses." Then she presented a small and a big clay ball one and said: "Here we have a small clay ball and a big one. If you want, you can touch them [participants were invited to touch them]" (see Figure 1, Familiarization). The experimenter then asked the participant: "If I put the balls in the two glasses, their level of water will rise, do you think that it will rise more in this glass [The experimenter points to one of the glasses]? Do you think it will rise more in this glass [The experimenter points to the other glass]? Or it will rise the same in the two glasses?" All the tasks relied on the same instructions. Only in the familiarization phase were the two balls dropped in the glasses so that the participants were able to observe the result of the immersion.

The Generation 1 participant was then invited to complete the task with a metal ball and a clay ball ("Here we have two identical balls but one is made of clay and the other one of metal.") (see Figure 1, Task). The difference in weight was indicated to the participants ("The 


\section{EVIDENTIALITY AND FLEXIBILITY OF SOURCE REPORTING}

metal ball is heavier than the clay ball.") and they were invited to experience it on their own by touching and weighing the balls ("You can take the balls into your hands so you can feel the difference of weigh [participants were invited to take them]"). Then, they were asked to solve the problem. Depending on their answer to the question of in which glass will the water rise more, the participants were exposed to different situations. If the Generation 1 participant gave the correct answer, she was invited to justify her response ("Why do you think that the level of water rises the same in the two glasses?"). If the Generation 1 participant gave an incorrect answer she was exposed randomly to one of the two following conditions: the Authority Condition in which the experimenter gave solely the correct answer with no further explanation ("In fact, the water rises the same in the two glasses."); or the Argument Condition in which the experimenter supported her answer with an argument ("In fact, the water rises the same in the two glasses because the two balls are the same size."). Then the Generation 2 participant was invited in the room and she was introduced to the same tasks ("Now we will let a fellow who will solve the same task. If she is wrong, I will ask you to explain to her which is the correct answer.").

Phase 2. The second phase starts with the same familiarization and experimental tasks as in Phase 1, but for the Generation 2 participant. Then, depending on this participant's answer to the experimental task, she was exposed to two different conditions. If she gave the correct answer, the experimenter asked the Generation 2 participant to justify her answer. If the Generation 2 participant gave an incorrect answer, the Generation 1 participant was invited to explain the correct answer to her ("Your fellow was wrong, could you please explain the answer to him/her."). We recorded and later coded the reasons produced by the Generation 1 participants to explain to the Generation 2 participants the correct answer.

\section{Results}




\section{EVIDENTIALITY AND FLEXIBILITY OF SOURCE REPORTING}

All the answers were transcribed in their respective native language and then translated to Spanish. In order to access both the reasons provided by the participants and the evidentials contained in those reasons we conducted two independent coding processes. First, a coding of the reasons based on the Spanish translation and second, a coding of the evidentials contained in the answers, based on the transcriptions in Quichua and Cha'palaa. The meanings and contexts of use of the evidentials in the experimental context were based on observations of their usage in natural speech corpora outside the experimental context, where evidential marking is frequent in everyday discourse; examples of natural speech usages are provided for each evidential marker or construction for the respective languages.

\section{Ecuadorian Highland Quichua}

In the Quichua community, $75 \%$ of the Generation 2 participants (36 out of 48 ) initially provided the incorrect answer. Thus, the results are based on the 36 interactions in which Generation 1 participants had to explain to Generation 2 participants the correct answer, distributed as following: in $11(31 \%)$ cases, the Generation 1 participants had provided the correct answer on their own; in $12(23 \%)$ cases, the Generation 1 participants had acquired the correct answer from the experimenter (Authority condition); in 13 (36\%) cases, the Generation 1 participants had acquired the correct answer and the correct argument from the experimenter (Argument condition).

The main outcome of interest is the type of reason provided by the Generation 1 participant to convince the Generation 2 participant to accept the correct answer, as a function of the condition (Authority or Argument).

These reasons (in their Spanish translations) were first coded according to the following scheme: 


\section{EVIDENTIALITY AND FLEXIBILITY OF SOURCE REPORTING}

Correct argument: the participant explains that the water is going to rise as much in the two glasses by saying that the balls are the same size.

Bolster: the participant only expresses confidence (e.g. "I am sure"; "According to me"), or reiterates the answer (e.g. "The level rises as much in both glasses")

Authority: the participant mentions that she holds the answer from the experimenter (e.g. "In both, just like she said").

Confusion: confused answer, not clearly interpretable in terms of the other categories.

In the few cases in which the reasons might be coded in two different categories, the reasons were coded as follows: any mention of the authority of the experimenter results in the reason being coded as Authority; otherwise, any mention of the correct argument results in the reason being coded as Correct argument. This coding was used to make sure not to hide any Authority reason. In any case, only two reasons contained several elements. Table 1 presents the distribution of the reasons as a function of how Generation 1 participants had acquired the correct answer.

Table 1

Type of reason provided by the Generation 1 participant to convince the Generation 2 participant, as a function of how the Generation 1 participant had acquired the correct answer.

\begin{tabular}{c|c|c|c|c}
\hline $\begin{array}{c}\text { Condition of the Generation 1 } \\
\text { participant }\end{array}$ & $\begin{array}{c}\text { Correct } \\
\text { argument }\end{array}$ & Bolster & Authority & Confusion \\
\hline $\begin{array}{c}\text { Provided the correct answer } \\
\text { on their own }\end{array}$ & 9 & 2 & 0 & 0 \\
\hline Authority condition & 7 & 4 & 0 & 1 \\
\hline Argument condition & 7 & 2 & 3 & 1 \\
\hline
\end{tabular}




\begin{tabular}{l|l|l|l|l}
\hline TOTAL & 23 & 8 & 3 & 2 \\
\hline
\end{tabular}

Most participants in the Authority condition were able to find the correct argument on their own, after being provided with the correct answer. As a result, our hypothesis that these participants would be more likely to accurately relay the social source of their answer was not supported. On the whole, among the participants who acquired the correct answer socially (N $=25$ ), only three mentioned the social source of their belief.

The reasons provided by the participants were also coded according to the evidentials they contained in the transcribed response in the native language. Quechuan evidential systems all share some elements, but they have changed over time, so the system that Faller (2002) describes in detail for Cuzco Quechua is not quite the same as that seen in Ecuadorian Highland Quichua (for example, the reportative function of Cuzco -shi has been taken over by the speech verb, usually in a frozen third person form nin). These were the different evidential options used by Quichua speakers during the task, with an example of each selected from their usage in natural speech corpora, outside of the experimental context:

Unmarked: no evidential was used (direct evidence by default).

For example, a person who has actually been to the place being discussed might simply state something about it without any evidential marking, implying that their knowledge is firsthand:

jatun feria tiya-n chay-kuna-pi.

big fair exist- $3^{\mathrm{RD}}$.PERSON there-PLURAL-in

There is a big fair in that area (and I generally imply I have been there).

QUSF2018_12_23S1_14103001

\footnotetext{
${ }^{1}$ Examples come from the Cha'palaa and Quichua video language documentation corpora. The Cha'palaa corpus is archived at the Language Archive hosted at the Max Planck Institute for Psycholinguistics, Nijmegen:
} 


\section{EVIDENTIALITY AND FLEXIBILITY OF SOURCE REPORTING}

Good evidence: the morpheme "mi" was used, indicating a good/personal evidence (direct evidence).

For example, someone who is specifying that they have personally visited the place mentioned and seen the state of affairs in question could say the following:

kay-pi-mi kawsa-rka jawa urku-man

here-in-GOOD.EVIDENCE live-PAST.TENSE high mountain-towards

He lived here in the high mountains (and I specify that I saw it myself).

QUSF2018_04_21S1_408096

Reportative: the morpheme "ni" was used, indicating second-hand information (indirect evidence).

Someone who had not personally witnessed the state or events in question would tend to express their information source with a reportative based on the $3^{\text {rd }}$ person form of the speech verb:

chay-ka cusina-man ri-shka nin

there-TOPIC kitchen-towards go-PERFECTIVE REPORTATIVE

Then he had gone to the kitchen (I was told).

QUSF2019_03_04S1_160660

Inferential: the morpheme "shka" was used, indicating inferential evidence (indirect evidence).

https://archive.mpi.nl/tla/. The Ecuadorian Highland Quichua corpus is archived at the Endangered Language Archive (ELAR): https://elar.soas.ac.uk/. Corpora can be accessed for community or research purposes by contacting the archive managers or Simeon Floyd. The first part of the unique identifiers included with the examples correspond to the date and session of the recording (e.g. QUSF2018_12_23S1) and the second part indicates when the extract occurred during the recording, measured in milliseconds (e.g. 1410300). 


\section{EVIDENTIALITY AND FLEXIBILITY OF SOURCE REPORTING}

This evidential could be used when a person is communicating that they are updating their beliefs about an ongoing state of affairs on the basis of something they have just learned (for instance, the utterance below comes directly after the statement "I though he only had four children"):

Kayna riku-ni, seis-ta chari-k ka-shka-ka. yesterday see- ${ }^{\mathrm{ST}}$.PERSON six-DIRECT.OBJ have-NOMINALIZER be-INFERENTIAL-TOPIC Yesterday I saw that he had six (children) (and while this has been the case for a while, I am just now learning of it).

QUSF2018_02_24S1_3076490

It is sometimes possible for a sentence to combine evidential markers, but this rarely occurred in the data, and in the few cases in which it did (three cases), the marking seen on the initial main verb was used for coding. Table 2 presents the distribution of the different types of evidential marking as a function of how the Generation 1 participant had acquired the correct answer (the two participants who gave a confused answer were excluded from this codification). We come back below to an explanation of these results.

Table 2

Type of evidentials provided by the Generation 1 participant as a function of how she had acquired the correct answer.

\begin{tabular}{c|c|c|c|c}
\hline $\begin{array}{c}\text { Condition of the Generation 1 } \\
\text { participant }\end{array}$ & Unmarked & Good evidence & Reportative & Inferential \\
\hline $\begin{array}{c}\text { Provided the correct answer on } \\
\text { their own }\end{array}$ & 6 & 3 & 1 & 1 \\
\hline Authority condition & 10 & 0 & 0 & 1 \\
\hline Argument condition & 7 & 2 & 0 & 2 \\
\hline TOTAL & 21 & 5 & 1 & 4 \\
\hline
\end{tabular}




\section{EVIDENTIALITY AND FLEXIBILITY OF SOURCE REPORTING}

\section{Cha'palaa}

In the Chachi community, $62 \%$ of the Generation 2 participants (30 out of 48 ) initially provided the incorrect answer. Thus, the results are based on the 30 interactions in which Generation 1 participants had to explain to Generation 2 participants the correct answer, distributed as following: in $15(50 \%)$ cases, the Generation 1 participants had provided the correct answer on their own; in $5(17 \%)$ cases, the Generation 1 participants had acquired the correct answer from the experimenter (Authority condition); in 10 (33\%) cases, the

Generation 1 participants had acquired the correct answer and the correct argument from the experimenter (Argument condition).

These reasons were first coded following the same scheme as for the Quichua participants. Table 3 presents the distribution of reasons provided by Generation 1 participants as a function of how they acquired the correct answer (two participants failed to provide an answer) (coding based on the Spanish translation).

\section{Table 3}

Type of reason provided by the Generation 1 participant to convince the Generation 2 participant, as a function of how the Generation 1 participant had acquired the correct answer.

\begin{tabular}{c|c|c|c|c}
\hline $\begin{array}{c}\text { Condition of the Generation 1 } \\
\text { participant }\end{array}$ & $\begin{array}{c}\text { Correct } \\
\text { argument }\end{array}$ & Bolster & Authority & Confusion \\
\hline $\begin{array}{c}\text { Provided the correct answer } \\
\text { on their own }\end{array}$ & 11 & 3 & 0 & 0 \\
\hline Authority condition & 2 & 1 & 0 & 2 \\
\hline Argument condition & 5 & 1 & 0 & 3 \\
\hline TOTAL & 18 & 5 & 0 & 5 \\
\hline
\end{tabular}




\section{EVIDENTIALITY AND FLEXIBILITY OF SOURCE REPORTING}

The main finding is that even among the participants who had socially acquired the correct answer out of their interaction with the experimenter, none mentioned a social or reportative source in their arguments.

The reasons were then coded according to the evidentials they contained (based on the native language assertions):

Unmarked: no evidential was used (direct by default).

For instance, here is an individual speaking about their personal experience providing for their children's education, using evidentially unmarked general statements:

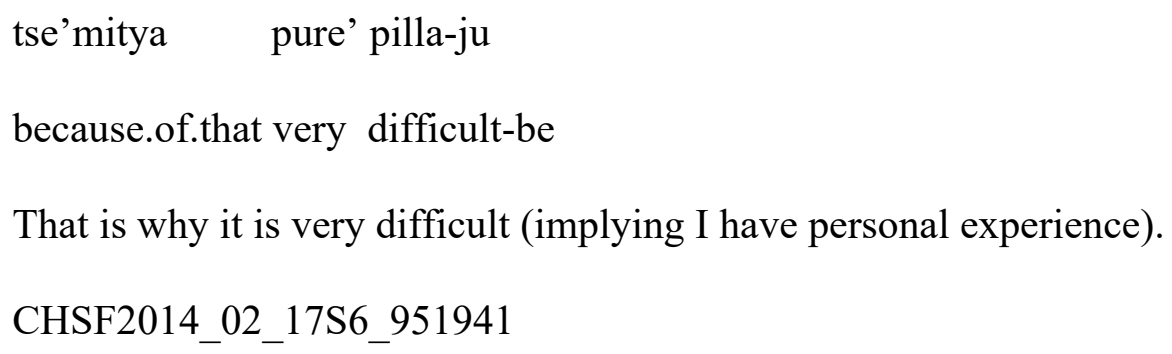

Declarative: the declarative "mi" was reported, indicating a neutral stance on evidence (direct by default).

When people use this marker, they make no specific claim about the nature of their evidence, but its usage is associated with direct evidence since no mediation of evidence is implied. In this example the speaker had direct evidence but was not personally involved:
ishkala kush-mi
yai-chi-ya
ma hora nan-sha
liquor drink-DECLARATIVE 3RD.PERSON.PLURAL-DATIVE-TOPIC one hour pass-in They drink liquor, those guys, any time of day.
CHSF2011_06_25S1_2861176 


\section{EVIDENTIALITY AND FLEXIBILITY OF SOURCE REPORTING}

Counter assertive: when the interactive marker "ba" was used, indicating a stance opposing some previous assumption or proposition (associated with direct evidence). For example, the following statement was spoken directly after another person asked "Doesn't he have a wife?", implying that he assumed the person in question was married. To counter this implicature, the second person responded using the counter-assertive, implying that they have direct evidence to the contrary:

$$
\text { miya-tju-ba }
$$

have-NEGATIVE-COUNTER.ASSERTIVE

He doesn't have (a wife).

CHSF2011_01_11S3_5102291

Non-egophoric: the declarative non-egophoric "we" was used, indicating that the speaker does not have evidence based on being involved as an agent (not explicitly direct).

In this case one child was inquiring to another about whether there was any food left over, and the second child informed her that there was not—-she may know this from direct experience.

Ju-tyu-we

be-NEGATIVE-NON.EGOPHORIC

There aren't any (and I am not involved).

CHSF2011_01_11S2_845791

Dubitative: the epistemic marker "meete(e)" was used, indicating potentially not solid evidence (associated with indirect evidence).

In the example below the speaker did not have any direct evidence of when the person in question had left, but was speculating that it may have been today. 


\section{EVIDENTIALITY AND FLEXIBILITY OF SOURCE REPORTING}

uma-a mi-i-meetee manen

today-TOPIC again-go-DUBITATIVE again

He may have left again today (but I do not have direct evidence).

CHSF2012_01_06_1027692

Table 4 presents the distribution of the different types of evidentials as a function of how the Generation 1 participant had acquired the correct answer (the five participants who gave a confused answer were excluded from this codification).

Table 4

Type of evidentials provided by the Generation 1 participant as a function of how she had acquired the correct answer.

\begin{tabular}{c|c|c|c|c|c}
\hline $\begin{array}{c}\text { Condition of the Generation 1 } \\
\text { participant }\end{array}$ & Unmarked & Declarative & $\begin{array}{c}\text { Counter } \\
\text { assertive }\end{array}$ & $\begin{array}{c}\text { Non- } \\
\text { egophoric }\end{array}$ & Dubitative \\
\hline $\begin{array}{c}\text { Provided the correct answer } \\
\text { on their own }\end{array}$ & 6 & 1 & 1 & 5 & 1 \\
\hline Authority condition & 1 & 0 & 0 & 0 & 2 \\
\hline Argument condition & 4 & 0 & 1 & 1 & 0 \\
\hline TOTAL & 11 & 1 & 2 & 6 & 3 \\
\hline
\end{tabular}

\section{Discussion}

Looking at explicit mentions of sources and at evidential markers, we find that both the Quichua and the Chachi participants who acquired the information about the experimental objects from other people during the session rarely mentioned the social sources of their statements. Among the 39 Generation 1 participants who had initially provided an incorrect answer, and who were then provided with the correct answer by the experimenter, only three 


\section{EVIDENTIALITY AND FLEXIBILITY OF SOURCE REPORTING}

mentioned the experimenter when they had to convince another participant to accept the correct answer.

The least surprising feature of these results is that participants failed to explicitly report the social source of their answer when they had been provided with the correct argument (Argument condition). Moreover, over half ( 7 out of 12) of the participants simply provided with the correct answer, and not the correct argument (Authority condition) were able to infer the correct argument on their own, which might help explain why these participants also rarely explicitly reported the social source of their answer: even though the experimenter provided indirect evidence, there is also an element of direct experience - their own understanding of the problem - that participants may emphasize over the socially acquired elements of the information source.

More surprising is that none of the participants who had acquired their answer socially used reportative evidential marking, even though they had acquired the correct answer socially. Instead, most used an unmarked form. In languages with evidential markings, unmarked forms may imply direct evidence (Aikhenvald, 2004, p. 73; for discussion of a similar system in a related language, see Grzech, 2016, pp. 328-341), and in both Quichua and Cha'palaa unmarked statements are generally understood as based on direct experience, if not entirely specified for source. It thus appears that speakers of languages with evidentials are not any less capable of flexibility in the transmission of source information than other participants. Despite the requirements of these languages to choose one evidential perspective or another, rather than rigidly using one type of evidential marking for one type of situation, speakers of languages with evidentials may frame information source in different ways.

\section{Experiment 2}




\section{EVIDENTIALITY AND FLEXIBILITY OF SOURCE REPORTING}

The goal of Experiment 2 was to extend the results of Experiment 1 by using a task in which it would be more difficult for the participants to argue for the correct answer without mentioning the social source of their beliefs. We used a perceptual task, in which in substantial minority of participants in the U.S. and Japan mention the social sources of their beliefs (Mercier et al., 2019).

\section{Method}

\section{Participants}

The 96 Quichua speakers who took part in Experiment 1.

\section{Materials}

Since one of our goals was to find problems for which participants might be forced to argue about the source of their belief, rather than their content, we used low-level perceptual problems. These problems were drawn from Koriat $(2011)^{2}$ and consisted of pairs of lines (see Figure 2). The task was to tell which of the two lines was longer. Previous data suggested that some comparisons were easy, while others were difficult. We planned on using the latter as material for which most participants would initially provide an incorrect answer, which would then be corrected by a suggestion coming from a different source (a competent participant). Previous experiments in the U.S. and Japan had shown that, at least for these participants, the stimuli had the required properties (Mercier et al., 2019).

\section{Procedure}

Participants had to compare ten pairs of lines: when presenting each pair of lines, the experimenter asked the participant: "Which line is the longest?" For the first nine pairs, after they provided an initial answer, participants were told the answer given by someone described as being another participant ("To this question, someone from another community answered

\footnotetext{
${ }^{2}$ We thank Asher Koriat for kindly sharing these stimuli with us.
} 


\section{EVIDENTIALITY AND FLEXIBILITY OF SOURCE REPORTING}

that it was the A [B]"). They had the opportunity to change their mind on the basis of this information, being asked "What is your final answer?". Participants then received feedback on whether they, as well as the other participant, had provided the correct answer (e.g. "The correct response is A. The answer from the person from the other community was correct and yours was incorrect"). For the tenth and last pair — which was a difficult pair — the procedure was similar, except that before receiving feedback on the correctness of their answer, participants were told that their answer would be passed on to another participant, and that they should provide an argument to support it. In this version of the experiment, participants received the answers from a previous participant who was always right. As a result, when they reached the tenth question, they knew that the other participant has been consistently right on the first nine pairs, including four difficult pairs - we will call this participant the authority (see Figure 2).

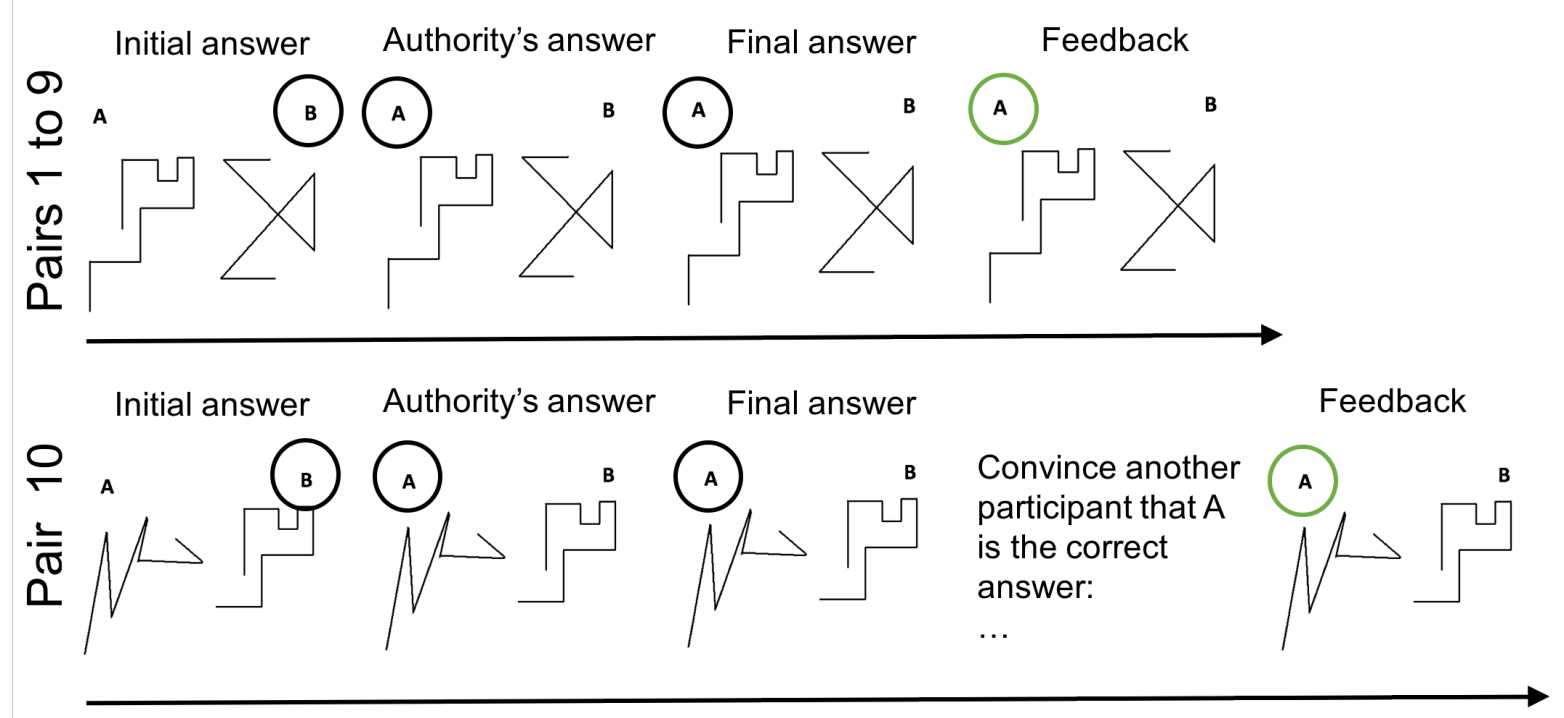

Figure 2. Procedure for Experiment 2. Figure extracted from Mercier et al. (2019).

\section{Results}




\section{EVIDENTIALITY AND FLEXIBILITY OF SOURCE REPORTING}

The same strategy of coding as reported in Experiment 1 was employed to capture both the reasons provided by the participants, and the evidentials they used.

On the tenth pair, 76 participants (79\%) initially provided the incorrect answer. Of these 76 participants, 37 (49\%) changed their mind to adopt the answer provided by the authority. These numbers are broadly similar to what had been observed in the U.S. and Japan (initial incorrect answers: U.S.: 78\%, Japan: 87\%; changing their minds: U.S.: 66\%, Japan: 64\%). Among the participants who had initially provided the correct answer, only one went against the authority's opinion and changed her mind to adopt the incorrect answer.

Our main interest was to determine if participants who had changed their mind on the last question, and thus had acquired their answer socially, would mention the social source of their belief when asked to provide a reason to defend this final answer. Accordingly, we focus on the reasons provided by the 37 participants who changed their minds and accepted the authority's answer.

All reasons (in their Spanish translations) were first coded according to the following scheme:

No argument: the participant gives no reason to support her answer (e.g. "I would say that it is ok").

Perceptual argument: the participant mentions characteristics of the drawing to support her answer (e.g. "This one has more lines").

Bolster: the participant only expresses confidence (e.g. "I am sure"; "According to me"), or reiterates the answer (e.g. "This one is longer").

Argument from authority: the participant mentions that she followed the answer of the other participant (e.g. "Because the other person said so"). 


\section{EVIDENTIALITY AND FLEXIBILITY OF SOURCE REPORTING}

Disclaimer: the participant expresses uncertainty (e.g. "I am not sure"; "I don’t know what to say").

Table 5 shows the distribution of the different types of reasons provided by the participants as a function of the condition (we removed the two participants who failed to provide an argument, including one participant who adopted the authority's answer).

Table 5

Type of reasons produced by the participants as a function of the condition.

\begin{tabular}{c|c|c|c|c}
\hline & $\begin{array}{c}\text { Perceptual } \\
\text { argument }\end{array}$ & Bolster & $\begin{array}{c}\text { Argument from } \\
\text { authority }\end{array}$ & Disclaimer \\
\hline Sticks to initially correct answer & 12 & 7 & 0 & 0 \\
\hline Adopts incorrect answer & 1 & 0 & 0 & 0 \\
\hline Adopts the authority's answer & $\mathbf{1 9}$ & $\mathbf{9}$ & $\mathbf{6}$ & $\mathbf{2}$ \\
\hline Sticks to initially incorrect answer & 19 & 16 & 1 & 2 \\
\hline Total & 51 & 32 & 7 & 4 \\
\hline
\end{tabular}

The reasons were then coded according to the evidentials they contained (from the transcription in their native language). The coding was similar to that used for the Quichua population in Experiment 1, with the addition of a conjectural category which had not been observed in Experiment 1.

Conjectural: the morpheme "cha" was used, indicating evidence based on conjecture from general knowledge.

The person making the statement in the following example is expressing that they are drawing not from personal knowledge but from broader assumptions:

shina-cha ka-n 


\section{EVIDENTIALITY AND FLEXIBILITY OF SOURCE REPORTING}

like.that-CONJECTURAL be-3 $3^{\mathrm{RD}}$.PERSON

That's how it must be (it would generally be assumed, but I can't personally confirm).

QUSF2018_02_18S1_2041990

Table 6 presents the distribution of the different types of evidentials as a function of the condition.

Table 6

Type of evidentials produced as a function of the condition.

\begin{tabular}{c|c|c|c|c}
\hline & Unmarked & $\begin{array}{c}\text { Good/personal } \\
\text { evidence }\end{array}$ & Reportative & Conjectural \\
\hline Sticks to initially correct answer & 13 & 3 & 0 & 2 \\
\hline Adopts incorrect answer & 0 & 1 & 0 & 0 \\
\hline Adopts the authority's answer & $\mathbf{3 0}$ & $\mathbf{4}$ & $\mathbf{2}$ & $\mathbf{0}$ \\
\hline Sticks to initially incorrect answer & 34 & 3 & 1 & 1 \\
\hline Total & 77 & 11 & 3 & 3 \\
\hline
\end{tabular}

\section{Discussion}

In Experiment 237 participants accepted a correct answer that was socially

transmitted. However, as in Experiment 1, when they had to transmit this correct answer, few mentioned the social source of their beliefs, whether explicitly $(6$, or $16 \%)$, or through a reportative evidential (2, or 5\%). This result is much more striking than in Experiment 1 since, in Experiment 2, participants had acquired the correct answer through deference, and there was no correct argument to reconstruct. Instead, most participants (19, or 51\%) used perceptual arguments, that is, arguments that drew on the shape of the lines - even thought they had initially judged to be shorter the line they were then offering as a correct answer. 


\section{EVIDENTIALITY AND FLEXIBILITY OF SOURCE REPORTING}

As in Experiment 1, most participants (30, or 81\%) used an unmarked evidential form. Since this was in line with their explicit expressions, mostly consisting of perceptual arguments or of bolsters, further suggesting that unmarked forms generally imply direct evidence.

\section{Conclusion}

Several experiments had shown that once typical psychology participants have socially acquired information, they often behave flexibly when it comes to attributing sources, choosing to present the information as if they had acquired it personally rather than reveal that it was communicated to them by someone else (Claidière et al., 2017; Dockendorff \& Mercier, in prep; Mercier et al., 2019). Two of these experiments were adapted and conducted in two small-scale populations speaking languages with evidential marking: speakers of Ecuadorian Highland Quichua and Cha'palaa. As argued above, both of these factors-being members of small-scale societies, and speaking a language with evidential marking — might be thought to predict a reduced degree of flexibility in source attribution.

Contrary to such expectations, our results instead show strong evidence of flexible source reporting similar to that seen with typical psychology participants under similar conditions. Across the two experiments, and the two populations, many participants accepted someone else's answer as correct, yet, when they had to transmit this answer to another participant, very few reported the social sources of their answers: in Experiment 1, 3 out of 39 (8\%) did so, and 6 out of $37(16 \%)$ in Experiment 2. Instead, participants tended to present the answer as being the result of direct evidence. This was true both whether we analyzed the explicit reasons provided periphrastically, or the grammatical evidentials used.

Even though, due to the nature of the population studied, our sample sizes were not huge, the main for focus of this study wasn't the differences across conditions, but the 


\section{EVIDENTIALITY AND FLEXIBILITY OF SOURCE REPORTING}

comparison with the behavior of other populations reported in the literature. In this respect, our results clearly point to an absence of difference, and clearly demonstrate a high degree of flexibility in source reporting.

Our results thus suggest that flexibility in source reporting is a widespread practice across many societies, and that small-scale societies who speak languages with evidential systems are no exception. This is in line with previous experiments that also failed to show any correlation of evidentiality with increased accuracy in source reporting — although the flexibility in source reporting studied in these experiments were more subtle, and all the participants studied belong to large-scale populations (e.g. Turkey, Korea) (for review, see Ünal \& Papafragou, 2018). Our results thus support Aikhenvald's position (2014) that evidentiality as a grammatical system should not be conflated with the social practice of accurate or consistent reporting of information source (for discussions of flexible usages of evidentials within the Quechuan family, see Grzech, 2016; Hintz \& Hintz, 2017).

If grammatical evidentials do not imply rigid, mechanical reporting of information, then what besides grammar motivates their usage? The answers can probably be found in further investigation of the usage of evidential forms in social interactional contexts (San Roque, 2019; for examples of these types of studies on Cha'palaa and Quichua evidentials and related morphology, see Floyd, 2005, 2016, 2018). Studies of conversational interaction reveal how the selection of linguistic formats is modulated by subtle cues, such as epistemic distribution (i.e. who knows what information) (see Heritage, 2013), and research on naturalistic conversation in South American languages has shown how the use of evidentials can shift over the course of an interaction (see Gipper, 2014; Hintz \& Hintz, 2017). Many of these social interactional imperatives are similar across languages and societies, which might explain why we don't see obvious relativistic effects in which speakers of languages of evidential systems would behave radically more rigidly as compared to speakers of languages 


\section{EVIDENTIALITY AND FLEXIBILITY OF SOURCE REPORTING}

without evidential marking (see similar findings on similar patterns of language usage across diverse grammatical systems in Dingemanse et al., 2015; Floyd et al., 2018; Stivers et al., 2009).

As we argued at the outset, source flexibility can play a role in the spread of false information (e.g. Altay et al., submitted; Caplow, 1947; Morin, 1969). However, most source flexibility is not only not malicious, but also likely benign, reflecting the tradeoffs necessary to make one's utterances relevant—-tradeoffs between accuracy and conciseness, etc. The present experiments suggest that, under some conditions at least, evidentiality does not directly affect accuracy in source reporting. However, evidentiality might affect other factors relevant to the reporting of sources, for example by making it less cumbersome to specify one's sources, and thus easier to report sources (whether or not they are accurate). This could help explain why evidentials are relatively common across languages, even if they might not have a significant impact on the accuracy of source reporting. Further studies, in particular with a mix of observational and experimental data, should investigate the influence of evidentials on these different factors.

\section{References}

Aikhenvald, A. Y. (2004). Evidentiality. Oxford University Press.

Aikhenvald, A. Y. (2012). The Languages of the Amazon. Oxford University Press.

Aikhenvald, A. Y. (2014). The grammar of knowledge: A cross-linguistic view of evidentials and the expression of information source. In A. Y. Aikhenvald \& R. M. W. Dixon (Eds.), The Grammar of Knowledge: A Cross-Linguistic Typology (pp. 1-51). Oxford University Press. 


\section{EVIDENTIALITY AND FLEXIBILITY OF SOURCE REPORTING}

Aikhenvald, A. Y. (2016). Evidentiality in grammar. In D. Brown (Ed.), Encyclopedia of Language and Linguistics (pp. 320-325). Elsevier.

Altay, S., Claidière, N., \& Mercier, H. (submitted). It happened to a friend of a friend: Inaccurate source reporting in rumor diffusion.

Altay, S., \& Mercier, H. (in press). I found the solution! How we use sources to appear competent. Evolution and Human Behavior.

Aydin, C., \& Ceci, S. J. (2013). The role of culture and language in avoiding misinformation: Pilot findings. Behavioral Sciences \& the Law, 31(5), 559-573.

Boroditsky, L. (2003). Linguistic relativity. In L. Nadel (Ed.), Encyclopedia of cognitive science (pp. 917-921). MacMillan Press.

Caplow, T. (1947). Rumors in war. Social Forces, 298-302.

Castelain, T., Girotto, V., Jamet, F., \& Mercier, H. (2016). Evidence for benefits of argumentation in a Mayan indigenous population. Evolution and Human Behavior, $37(5), 337-342$.

Chafe, W. L., \& Nichols, J. (1986). Evidentiality: The linguistic coding of epistemology. Ablex.

Claidière, N., Trouche, E., \& Mercier, H. (2017). Argumentation and the diffusion of counterintuitive beliefs. Journal of Experimental Psychology: General, 146(7), 1052-1066.

Cole, M., Gay, J., Glick, J. A., \& Sharp, D. W. (1971). The cultural context of learning and thinking. Basic Books.

Cole, P. (1984). Imbabura quechua. Croom Helm.

Colloredo-Mansfeld, R. (1999). The Native Leisure Class. Chicago University Press. 


\section{EVIDENTIALITY AND FLEXIBILITY OF SOURCE REPORTING}

Dasen, P. R. (1972). Cross-cultural Piagetian research: A summary. Journal of Cross-Cultural Psychology, 3(1), 23-40.

de Haan, F. (1998). The category of evidentiality, Unpublished manuscript. University of New Mexico.

de Haan, F. (2013). Semantic Distinctions of Evidentiality. In M. S. Dryer \& M. Haspelmath (Eds.), The World Atlas of Language Structures Online. Max Planck Institute for Evolutionary Anthropology. http://wals.info/chapter/77

DeBoer, W. R., \& Blitz, J. H. (1991). Ceremonial centers of the Chachi. Expedition, 33(1), $53-62$.

DiFonzo, N., \& Bordia, P. (2002). Corporate rumor activity, belief and accuracy. Public Relations Review, 28(1), 1-19.

Dingemanse, M., Roberts, S. G., Baranova, J., Blythe, J., Drew, P., Floyd, S., Gisladottir, R. S., Kendrick, K. H., Levinson, S. C., Manrique, E., \& others. (2015). Universal principles in the repair of communication problems. PloS One, 10(9), e 0136100.

Dixon, R. M. (1997). The rise and fall of languages. Cambridge University Press.

Dockendorff, M., \& Mercier, H. (in prep). Argument transmission as the weak link in the correction of political misbeliefs.

Fadda, M., Allam, A., \& Schulz, P. J. (2015). Arguments and sources on Italian online forums on childhood vaccinations: Results of a content analysis. Vaccine, 33(51), 7152-7159.

Faller, M. T. (2002). Semantics and pragmatics of evidentials in Cuzco Quechua [stanford university]. http://personalpages.manchester.ac.uk/staff/Martina.T.Faller/documents/Thesis-A4.pdf 


\section{EVIDENTIALITY AND FLEXIBILITY OF SOURCE REPORTING}

Floyd, S. (2010). Discourse Forms and Social Categorization in Cha'palaa. University of Texas at Austin.

Floyd, S. (2014). 'We' as Social Categorization in Cha'palaa, a Language of Ecuador. In T.-S. Pavlidou (Ed.), Constructing Collectivity: “We” across languages and contexts (Vol. 239, pp. 135-158). John Benjamins Publishing Company.

Floyd, S. (2016). Insubordination in interaction: The Cha'palaa counter-assertive. In N. Evans \& H. Watanabe (Eds.), Dynamics of Insubordination (pp. 341-366). John Benjamins.

Floyd, S. (2018). Egophoricity and Argument Structure in Cha'palaa. In S. Floyd, L. San Roque, \& E. Norcliffe (Eds.), Typological Studies in Language (pp. 269-304). John Benjamins.

Floyd, S. (2005). The poetics of evidentiality in South American storytelling. Eighth Workshop on American Indian Languages (WAIL), 28-41. http://pubman.mpdl.mpg.de/pubman/item/escidoc:468575/component/escidoc:468573/ Floyd_vol16.pdf

Floyd, Simeon, Rossi, G., Baranova, J., Blythe, J., Dingemanse, M., Kendrick, K. H., Zinken, J., \& Enfield, N. J. (2018). Universals and cultural diversity in the expression of gratitude. Royal Society Open Science, 5(5), 180391.

Gipper, S. (2014). Intersubjective evidentials in Yurakaré: Evidence from conversational data and a first step toward a comparative perspective. Studies in Language. International Journal Sponsored by the Foundation "Foundations of Language," 38(4), 792-835.

Grzech, K. Z. (2016). Discourse enclitics in Tena Kichwa: A corpus-based account of information structure and epistemic meaning [PhD]. https://eprints.soas.ac.uk/24336/

Heritage, J. (2013). Epistemics in conversation. In J. Sidnell \& T. Stivers (Eds.), The Handbook of Conversation Analysis (pp. 370-394). Blackwell. 


\section{EVIDENTIALITY AND FLEXIBILITY OF SOURCE REPORTING}

Hintz, D. J., \& Hintz, D. M. (2017). The evidential category of mutual knowledge in Quechua. Lingua, 186, 88-109.

Imai, M., \& Gentner, D. (1997). A cross-linguistic study of early word meaning: Universal ontology and linguistic influence. Cognition, 62(2), 169-200.

Jijón y Caamaño, J. (1914). Los Aborígenes de La Provincia de Imbabura. Los Cayapas En Imbabura. Blass y Cía., Impresores.

Koriat, A. (2011). Subjective confidence in perceptual judgments: A test of the selfconsistency model. Journal of Experimental Psychology. General, 140(1), 117.

Kunda, Z. (1990). The case for motivated reasoning. Psychological Bulletin, 108, 480-498.

Loftus, E. F. (2005). Planting misinformation in the human mind: A 30-year investigation of the malleability of memory. Learning \& Memory, 12(4), 361-366.

Lucy, J. A. (1992). Language diversity and thought: A reformulation of the linguistic relativity hypothesis. Cambridge University Press.

Luria, A. R. (1976). Cognitive Development its Cultural and Social Foundations. Harvard University Press.

Mahr, J., \& Csibra, G. (2017). Why do we remember? The communicative function of episodic memory. Behavioral and Brain Sciences, 1-93.

Matsui, T., \& Yamamoto, T. (2013). Developing sensitivity to the sources of information: Early use of the Japanese quotative particles tte and to in mother-child conversation. Journal of Pragmatics, 59, 5-25.

Meisch, L. A. (2002). Andean Entrepreneurs Otavalo Merchants and Musicians in the Global Arena. University of Texas Press. 


\section{EVIDENTIALITY AND FLEXIBILITY OF SOURCE REPORTING}

Mercier, H. (2020). Not Born Yesterday: The Science of Who we Trust and What we Believe. Princeton University Press.

Mercier, H., Majima, Y., Claidière, N., \& Léone, J. (2019). Obstacles to the spread of unintuitive beliefs. Evolutionary Human Sciences, 1, e10.

Mercier, H., \& Sperber, D. (2011). Why do humans reason? Arguments for an argumentative theory. Behavioral and Brain Sciences, 34(2), 57-74.

Morin, E. (1969). La rumeur d'Orléans. Seuil.

Nuckolls, J. B., \& Michael, L. (Eds.). (2012). Evidentiality in Interaction; Special Issue of Pragmatics and Society 3:2. John Benjamins.

Nuckolls, J. B., \& Swanson, T. D. (2014). Earthy concreteness and anti-hypotheticalism in Amazonian Quichua discourse. Tipití: Journal of the Society for the Anthropology of Lowland South America, 12(1), 48-60.

Papafragou, A., Li, P., Choi, Y., \& Han, C. (2007). Evidentiality in language and cognition. Cognition, 103(2), 253-299.

Parsons, E. W. C. (1945). Peguche, canton of Otavalo, province of Imbabura, Ecuador: A study of Andean Indians. University of Chicago Press.

Piaget, J., \& Inhelder, B. (1974). The Child's Construction of Quantities. Routledge.

Robinson, E. J., \& Whitcombe, E. L. (2003). Children's suggestibility in relation to their understanding about sources of knowledge. Child Development, 74(1), 48-62.

San Roque, L. (2019). Evidentiality. Annual Review of Anthropology, 48.

San Roque, L., \& Loughnane, R. (2012). The New Guinea Highlands evidentiality area. Linguistic Typology, 16(1), 111-167. 


\section{EVIDENTIALITY AND FLEXIBILITY OF SOURCE REPORTING}

Schieffelin, B. B. (1995). Creating evidence. Pragmatics. Quarterly Publication of the International Pragmatics Association, 5(2), 225-243.

Shaw, A., \& Olson, K. (2015). Whose idea is it anyway? The importance of reputation in acknowledgement. Developmental Science, 18(3), 502-509.

Silver, I., \& Shaw, A. (2018). No harm, still foul: Concerns about reputation drive dislike of harmless plagiarizers. Cognitive Science, 42, 213-240.

Sperber, D., Clément, F., Heintz, C., Mascaro, O., Mercier, H., Origgi, G., \& Wilson, D. (2010). Epistemic vigilance. Mind and Language, 25(4), 359-393.

Stivers, T., Enfield, N. J., Brown, P., Englert, C., Hayashi, M., Heinemann, T., Hoymann, G., Rossano, F., De Ruiter, J. P., \& Yoon, K.-E. (2009). Universals and cultural variation in turn-taking in conversation. Proceedings of the National Academy of Sciences, 106(26), 10587-10592.

Tournadre, N., \& LaPolla, R. J. (2014). Towards a new approach to evidentiality: Issues and directions for research. Linguistics of the Tibeto-Burman Area, 37(2), 240-263.

Ünal, E., \& Papafragou, A. (2018). Evidentials, information sources and cognition. In A. Y. Aikhenvald (Ed.), The Oxford handbook of evidentiality (pp. 175-184). Oxford University Press.

Ünal, E., Pinto, A., Bunger, A., \& Papafragou, A. (2016). Monitoring sources of event memories: A cross-linguistic investigation. Journal of Memory and Language, 87, $157-176$.

Whitcombe, E. L., \& Robinson, E. J. (2000). Children's decisions about what to believe and their ability to report the source of their belief. Cognitive Development, 15(3), 329346. 


\section{EVIDENTIALITY AND FLEXIBILITY OF SOURCE REPORTING}

Wierzbicka, A. (1994). Semantics and epistemology: The meaning of 'evidentials' in a crosslinguistic perspective. Language Sciences, 16(1), 81-137. 


\section{EVIDENTIALITY AND FLEXIBILITY OF SOURCE REPORTING}

\section{Acknowledgements}

The authors acknowledge the support of the Quichua and Chachi community members who participated in the research leading to this article, including the Lema family of Peguche and the Quiñones de la Cruz family of Tsejpi, for their kind hospitality. We are also very grateful to our assistants, Lucila Oyagata Aguilar, Lucrecia San Nicolás de la Cruz and Johnny Pianchiche Añapa, for their precious help in translating the materials, conducting the experiments and the transcription and translation of the data collected.

\section{Funding}

This work was supported by several grants from the Agence Nationale de la Recherche [ANR-16-TERC-0001-01; Tremplin ERC VICCOM, 2017; ANR-17-EURE-0017] to Hugo Mercier and his department. The Vicerrectoria de Investigación from the University of Costa Rica and the Fundación UCR provide administrative and logistic support to Thomas Castelain. Support for fieldwork in Ecuador on which the linguistic elements of the experiments are based has also been funded by the US National Science Foundation, the Fulbright Foundation, the Max Planck Society, the Nederlandse Weteschappelik Organizatie, the Universidad San Francisco de Quito, and the European Research Council for supporting a Cha'palaa database and the Secretaria Nacional de Educación, Ciencia y Tecnología and the Endangered Languages Documentation Programme for a Quichua database, to Simeon Floyd. 